\title{
Erythroxylum campinense (Erythroxylaceae), espécie nova da Amazônia
}

\author{
A. Amaral Jr. ( ${ }^{(7)}$
}

\section{Resumo}

Descreve-se uma nova espécie de Erythroxylum P. Browne, Erythroxylum campinense Amaral Jr., para o Estado do Amazonas, Brasil.

Erythroxylum campinense Amaral Jr., sp. nov.

Sect. Rhabdophyllum O. E. Schulz (Figs. I $A-D$ e 2).

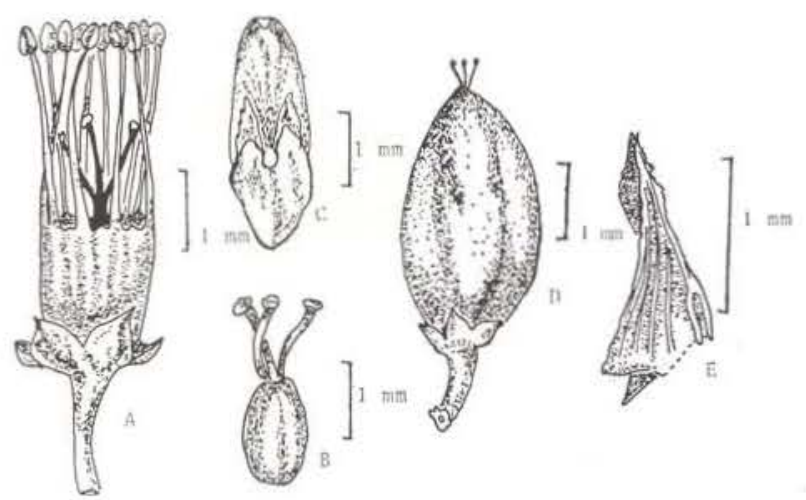

Fig. 1 - Erythroxylum campinense Amaral Jr. (G.T. Prance 18722); A, flor sem pétalas; B, ovário e estiletes; C, pétala; D, fruto; E, estipula.

Suffrutex vel frutex $0.5-1.0 \mathrm{~m}$ alt. Rami teretes, cortice subtestaceo fusco cinereo vel albescente. Ramuli horizontales, subcompressi, 1.5-2.5 mm lati. Folia mediocria, coriacea, late obovata, 38-67 mm longa, 24-37 mm lata, bası acuta, apice subtruncata vel retusa, utrinque opaca; costa media supra leviter subtus magis prominula, nervis lateralibus vix conspicuis; petiolus $2.5-4.2 \mathrm{~mm}$ longus, crassus. Stipula persistens, $1.0-2.0 \mathrm{~mm}$ longa, triangularis, brevissime 3-setulosa, remotiuscule striata, fim briata, ferruginea. Ramenta base innovatio num densa. Flores singules sed congesti in axillis ramentorum, pedicello 2.1-3.5 mm longo Calyx ad 2/3-3/4 partitus, laciniis semiovatis $0.7-1.0 \mathrm{~mm}$ longis. Petala $2.5-3.0 \mathrm{~mm}$ longa 1.0-1.3 $\mathrm{mm}$ lata, lamina oblongo elliptica. Flores brachystili: urceulus stamineus calyce Ion. gior; stamina 2.3-2.5 mm longa; ovarium ovatum urceolo aequilongum vel subaequilongum; styli $1.0 \mathrm{~mm}$ longi; stigmata depresso capitata. Drupa oblongo-ovata, sulcata, $8-9 \mathrm{~mm}$ longa, 3-4 $\mathrm{mm}$ diam.

hоцотүрus : Brasil, Amazonas, Reserva Experimental do Instituto Nacional de Pesquisas da A.mazònia, rodovia Manaus-Caracaraí, Km 61 . Campina on white sand. Shrub $1 \mathrm{~m}$ with erect trunk and trailing branches, flower white. Leg. G. T. Prance et al. $n .^{\circ} 18722$ (3.VIII.1973), INPA 42035 .

\section{MATERIAL ESTUDADO}

Brasil: Amazonas, Rodovia Manaus-Caracaraí, $\mathrm{Km}$ 62, Campina, arbusto de $1 / 2 \mathrm{~m}$ com frutos. Leg. G. Gottsberger \& W. Morawetz $\mathrm{n} .11-14475$ (14.IV. 1975), BOTU.

Subarbusto ou arbusto de $0,5-1,0 \mathrm{~m}$ de altura, ramos cilíndricos, córtex subtestáceo de

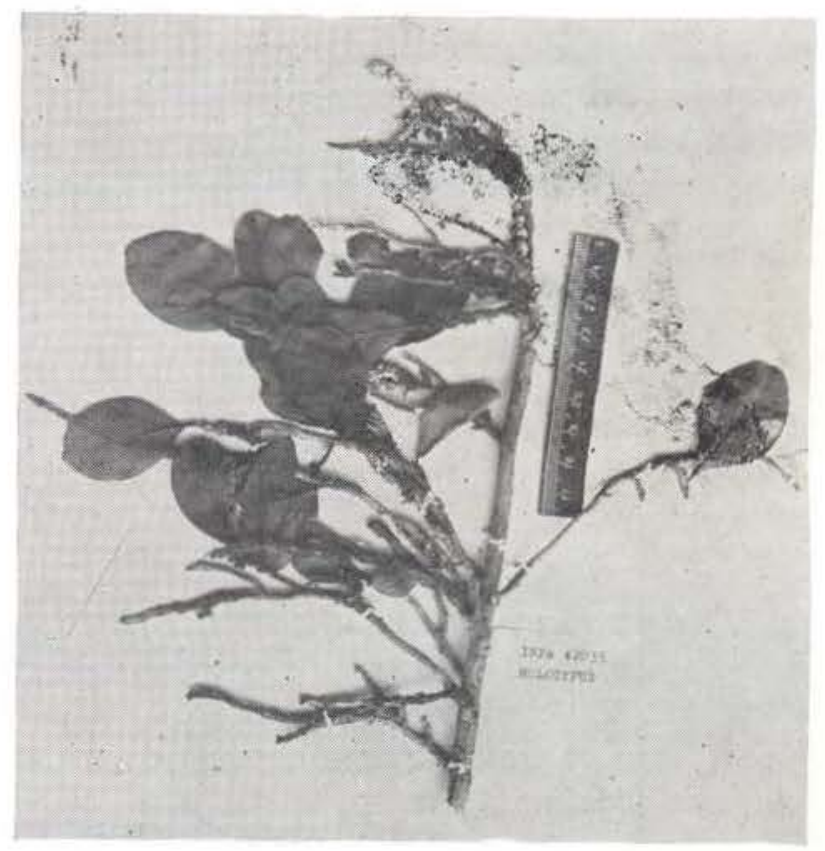

Fig. 2 - Erythroxylum campinense Amaral J., hábito da coleção típica (Prance et al, 18722, INPA 42.035).

(") - Departamento de Botânica da Faculdade de Ciências Médicas e Biológicas de Botucatu, Botucatu, São Paulo. 
coloração marrom-acinzentada ou esbranquiçada, dotado de fissuras longitudinais; raminhos mais ou menos horizontais pouco comprimidos ou subcomprimidos, com 1,5-2,5 mm de diâmetro. Folha pequena, coriácea, pecíolo crasso com 2,5-4,2 mm de comprimento, curtamente peciolada, mais ou menos largo-obovada, base aguda, ápice subtruncado ou retuso, levemen. te emarginada, $38-67 \mathrm{~mm}$ de comprimento por 24-37 $\mathrm{mm}$ de largura, nervura principal pouco saliente na face superior e mais pronunciada na inferior; nervuras laterais pouco visíveis, opaca em ambas as faces. Estípula (jovem) com 1,0-2,0 mm de comprimento, persistente, triangular, curtamente 3-setulosa, muito pouco estriada e fimbriada, de coloração ferrugínea; ramenta densa na base das inovaçōes. Flores solitárias nas axilas das ramentas, conges. tas. Pedicelo com 2,1-3,5 mm de comprimento, cálice partido de $2 / 3-3 / 4$ de seu comprimento, lacínios semi-ovados. Pétala de 2,5-3,0 mim de comprimento por 1,0-1,3 mm de largura, lâmina oblongo-elíptica, lígula com $1,3 \mathrm{~mm}$ de comprimento. Flores brevistilas: urcéolo estaminal pouco maior que o cálice; estames com 2,3-2,5 mm de comprimento, ovário eqüilongo ou subeqüilongo ao urcéolo, ovado. Estiletes livres, com 1,0 mm de comprimento, estígma depresso-capitado. Drupa de $8-9 \mathrm{~mm}$ de comprimento por 3-4 $\mathrm{mm}$ de diâmetro, oblongoovada, sulcada.

Segundo O. E. Schulz (1907), a secção Rhabdophyllum O. E. Schulz é composta de 41 espécies. Destas são citadas para a Amazônia: E. comosum O. E. Schulz, E. micranthum Bong., E. mucronatum Peyr., E. amplum Benth., E. amazonicum Peyr., E. paraense Peyr., E. citrifolium St. Hil., E. fimbriatum Peyr. e E. testaceum Peyr..

Novas espécies da secção Rhabdophyllum O. E. Schulz foram descritas posteriormente e, destas, apenas 3 são da Amazônia: E. kirkianum O. E. Schulz, descrito por O. E. Schulz (1932), que se trata de uma espécie da mata, coletada próximo a Manaus e que é tal como E. comosum O. E. Schulz e E. albertianum Kuhlmann \& Rodrigues muito característica por apresentar estípulas longas, de até $25 \mathrm{~mm}$ de comprimento. Huber (1909) descreveu E. filipes Hub., espécie esta afim de E. amplum
Benth.; finalmente J. G. Kuhimann e W. A. Rodrigues (1957) publicaram E. albertianum Kuhlmann \& Rodrigues. Quanto ao habitat, $E$. testaceum Peyr., E. mucronatum Peyr. e E. citrifolium St. Hil. são citados para as savanas da Amazônia e as demais espécies são todas da mata. Nenhuma referência sobre a ocorrência de espécies de Erythroxylum P. Browne na campina até o momento foi encontrada, bem como, nenhuma espécie se assemelha ao $E$. campinense Amaral Jr. tanto pela sua morfologia, como habitat.

Esse espiteto refrere-se à campina, local onde foi coletada.

Essa formação vegetal ocorre em peque. nas áreas no meio da floresta, em solo de areia branca lixiviada, regossólica e, é encon. trada no trecho norte de rio Negro, na regiāo de Manaus. Compõe-se de vegetação baixa, com arbustos muito ramificados, cobertos por epifitas, principalmente líquens, bromeliáceas e orquidáceas.

\section{Agradecimentos}

A Dra Irina Gentchujnicov pelas ilustrações que compõem o texto, à $\mathrm{Dr}^{\mathrm{a}}$ Graziela M. Barroso pela revisão do original, ao Instituto $\mathrm{Na}$. cional de Pesquisas da Amazônia pelas facilidades proporcionadas e, ao Dr. Gerhard Gottsberger que, por intermédio do Projeto Rondon e INPA, visitou e coletou material e dados das campinas.

\section{SUMMARY}

A new species of Erythroxylum P. Browne, Erythroxylum campinense Amaral Jr., irom the State of Amazonas, Brasil is described, and illustrated.

\section{BIBLIOGRAFIA CITADA}

HUBFR, J.

1909 - Materiais para a Flora Amazônica VII. Bol. Mus. Goeldi, $5: 414-422$.

Kuhlmann, J.G. \& William A. Rodrigues

1957 - Novitates Florae Amazonica. Erythroxylaceae. Publ. Inst. Nac. Pesq. Amaz. Bot., $5: 3-4$.

SCHULZ, O.E.

1907 - Erythroxylaceae. In: Engler - Das Pflanzenr. 4(134): 1-176.

SCHULZ, O.E

1932 - E. Kirkianum. in: Fedd. - Repert., $3: 1-79$. 